\title{
Serum Copper, Zinc and Lipid Peroxidation in Pregnant Women with Preeclampsia in Gorgan
}

\author{
Arash Rafeeinia ${ }^{1}$, Afsaneh Tabandeh ${ }^{2}$, Safoura Khajeniazi ${ }^{3}$ and Abdol J. Marjani ${ }^{4, *}$ \\ ${ }^{I}$ Department of Biochemistry and Biophysics, Metabolic Disorders Research Center, Gorgan Faculty of Medicine, \\ Golestan University of Medical Sciences, Gorgan, Golestan Province, Iran \\ ${ }^{2}$ Department of Gynecology, Gorgan Faculty of Medicine, Golestan University of Medical Sciences, Gorgan, Golestan \\ Province, Iran \\ ${ }^{3}$ Department of Medical Biotechnology, Gorgan Faculty of Advanced Medical Science Technology, Golestan University \\ of Medical Sciences, Gorgan, Golestan Province, Iran \\ ${ }^{4}$ Department of Biochemistry and Biophysics, Metabolic Disorders Research Center, Gorgan Faculty of Medicine, \\ Golestan University of Medical Sciences, Gorgan, Golestan Province, Iran
}

\begin{abstract}
The aim of study was to assay serum copper, zinc and lipid peroxidation levels in pregnant women with and without preeclampsia. There were significant differences between systolic, diastolic blood pressures and copper, $\mathrm{Cu} / \mathrm{Zn}$ ratio and malondialdehyde among two groups. There were significant differences in weight, pre-pregnancy body mass index, systolic, diastolic blood pressures and copper, $\mathrm{Cu} / \mathrm{Zn}$ ratio and malondialdehyde levels when compared to healthy pregnant women with mild and severe preeclampsia patients. A positive correlation was observed between systolic and diastolic blood pressure and copper, malondialdehyde and $\mathrm{Cu} / \mathrm{Zn}$ ratio. Copper and malondialdehyde may play a role in the pathophysiology of preeclampsia.
\end{abstract}

Keywords: Copper, Zinc, Lipid peroxidation, Preeclampsia

\section{INTRODUCTION}

Preeclampsia is a disorder that can influence the mother and the fetus during pregnancy. Its symptoms are characterized by high blood pressure, swelling of lower extremities and protein in the urine, sudden weight gain, headaches and changes in vision. High blood pressure and preeclampsia take place in the late second or third trimesters $[1,2]$. Preeclampsia complicates $2-8 \%$ of all pregnancies [3]. It has been shown that the incidence of preeclampsia in the developing countries is higher than developed countries [4]. Preeclampsia influences $3.4 \%$ of all pregnancies in developing countries. World Health Organization reported that preeclampsia is a major reason of mother and fetus morbidity and mortality [5]. Increased blood pressure is the important sign for the acuteness of preeclampsia. The blood pressure level may be regulated with the use of antihypertensive medicines [6]. Studies on preeclampsia women have revealed that lipid peroxidation levels are increased in blood [7, 8-12] and Placenta [13-15] of these subjects. Some studies have shown elevated reactive oxidative species and placenta oxidative stress were seen during delivery and the period following birth [16] and

*Address correspondence to this author at the Department of Biochemistry and Biophysics, Metabolic Disorders Research Center, Gorgan Faculty of Medicine, Golestan_University of Medical Sciences, Gorgan, Golestan Province, Iran; Tel/Fax: +98(171)4421651 \& 4440225;

E-mail: abdoljalal@yahoo.com endothelial dysfunction leading to preeclampsia [17], respectively. Micronutrients deficiencies are usually found in pregnant women [18]. Deficiency of some trace elements may make women susceptible to the development of preeclampsia. Some of these trace elements can regulate the balance between free radicals and antioxidants [19]. Trace elements like copper $(\mathrm{Cu})$ and zinc $(\mathrm{Zn})$ are essential trace elements. These elements may contribute in the development of some diseases like preeclampsia [20].

Copper is an important trace element which takes parts in structure of many enzymes like lysyl oxidase, cytochrome coxidase, tyrosinase, dopamine- $\beta$-hydroxylase, peptidylglycine alpha-amidating monooxygenase, monoamine oxidase, ceruloplasmin, and copper-zinc superoxide dismutase. Many different studies have shown that there is an association between occurrence of preeclampsia and trace elements, while some other studies have not shown such association [21]. Copper can produce the highly reactive hydroxyl radical. The generation of this radical can begin lipid peroxidation process which may cause endothelial cell damage [22]. Many studies have shown that copper concentration increased in preeclampsia patients [7].

Alteration of zinc ( $\mathrm{Zn}$ ) may cause pathogenesis of several diseases [23]. Normal homeostasis of $\mathrm{Zn}$ is regulated by the actions of $\mathrm{Zn}$ transporters like zinc-related protein. These transporters control the level of $\mathrm{Zn}$ inside and outside the cell $[24,25]$. It has been shown that zinc performs a considerable role for optimal function of more than 300 different enzymes 
[26]. Some studies have indicated that decreased zinc concentrations collaborated with fetal malformations, fetus growth restriction, preterm delivery, preeclampsia, and bleeding after delivery $[27,28]$. Serum or placental Zn levels have shown to be low $[7,29]$ or without change $[30,31]$ in preeclampsia women. It has been revealed that concentrations of zinc and copper reduced in pre-eclampsia patients [18, 32] while study of Ugwuja et al. [33] showed that only copper was statistically different. There are also contradictory studies on the relationship between serum trace element levels and event of preeclampsia [34]. Studies have indicated the possible association of trace elements in fetal growth and evolvement and its relationship to newborn body weight, unhealthiness and rate of death [35]. The aim of this study was to assay serum level of copper and zinc status and lipid peroxidation in pregnant women with and without preeclampsia in Gorgan.

\section{MATERIAL AND METHODS}

\subsection{Study Population}

The study was carried out on 100 pregnant women, 50 healthy pregnant women with no complications of any disease and 50 women with preeclampsia in the third trimester were permitted to enter our study in the Sayyad shirazi educational Hospital, Gynecology Department of Golestan University of Medical Sciences, Gorgan, Iran, 2014. The study was approved by Ethical committees of the Research Deputy of University of Medical Sciences. Preeclampsia was defined as a blood pressure higher than $130 / 85 \mathrm{mmHg}$ and proteinuria with $1+$ or greater by dipstick. Severe preeclampsia was distinguished from mild preeclampsia when blood pressure is higher than 160/110 $\mathrm{mmHg}$ or proteinuria for mild preeclampsia $1+-3+$ and for severe preeclampsia greater than $3+$ on the dipstick [36].

Diagnosis of preeclampsia was directed by a gynecologist. Special designed questionnaire provided for collection of patient history. Exclusion criteria of subjects were as follow: History of diabetes mellitus, renal, cardiovascular, liver disease, endocrine disorder, any chronic illness. Weight was measured with minimal clothed, using digital scales. Height was measured with tape meter when the shoulder was in a normal position. Calculation of body mass index (BMI) was done by dividing weight in kilograms by height in meters squared [37].

\subsection{Blood Sample Preparation}

Five milliliter blood samples were taken from the peripheral vein for determination of trace elements and lipid peroxidation (the level of lipid peroxidation expressed as Malondialdehyde (MDA)) after an overnight fast during the third trimester of pregnancy. Blood samples were centrifuged at $3000 \mathrm{rpm}$ for $10 \mathrm{~min}$. The separated serum was used for malondialdehyde (MDA), zinc and copper measurement.

\subsection{Analysis}

Serum $\mathrm{Cu}$ and $\mathrm{Zn}$ concentrations were determined by Younglin AAS 8020 atomic absorption spectrophotometer.
Malondialdehyde was determined with Kei Satoh method [38].

\subsection{Statistical Analysis}

The results were expressed in mean \pm standard deviation. Statistical analyzation of data was done by SPSS- 16 version software. One way analysis of variance (ANOVA) followed by Post Hoc Tukey's test was utilized to test the differences between groups. Comparison of trace elements and MDA between preeclampsia patient and healthy groups was done using independent sample $\mathrm{t}$ test. Correlations between parameters were done by Pearson correlation test. $\mathrm{P}<0.05$ was accepted statistically significant.

\section{RESULTS AND DISCUSSION}

100 pregnant females were included in this study. The clinical characteristics, trace elements and malondialdehyde of the preeclampsia and healthy pregnant women are indicated in Table 1. The mean age of preeclampsia patient and healthy groups were $26.50 \pm 3.90$ and $27.10 \pm 4.60$ years, respectively. No significant differences were considered in maternal age, height, weight, gestational age and prepregnancy body mass index (BMI) among both groups. There were significant differences in systolic and diastolic blood pressures. Serum copper and MDA were significantly increased. No significant decrease was observed in zinc concentration among two groups. In subjects with preeclampsia, $\mathrm{Cu} / \mathrm{Zn}$ ratio was significantly higher than in healthy pregnant subjects. Serum MDA shows significant increase in preeclampsia patients. Clinical characteristic, trace elements and malondialdehyde of healthy pregnant women and patients with mild and severe preeclampsia are shown in Table 2. There is significant differences in weight, pre-pregnancy body mass index (BMI), systolic and diastolic blood pressures when healthy pregnant and mild pregnant women were compared with severe preeclampsia patients. There is significant elevation of copper, $\mathrm{Cu} / \mathrm{Zn}$ ratio and MDA levels when healthy pregnant women with patients with mild and severe preeclampsia are compared. Correlations between serum zinc, copper, MDA and Copper/ Zinc ratio and maternal age, gestational age, pre-pregnant body mass index, systolic and diastolic blood pressure of preeclampsia patients are shown in Table 3. We observed a significant positive correlation between systolic and diastolic blood pressure and serum copper, MDA and Copper/ Zinc ratio. There were no correlations between other parameters.

Preeclampsia can be associated with an oxidative stress disorder. Imbalance between antioxidant system in the human body and free radicals may cause cell functions and intracellular compartments modifications by oxidative stress [39]. Studies have been shown that there is considerable oxidative stress in normal pregnancies [40]. The exact reason of preeclampsia is not understood. Preeclampsia patients have shown an elevated MDA. The importance of this MDA in the pathogenesis of preeclampsia disease has been indicated [41-43]. Increased serum MDA concentrations in preeclampsia in our study are in agreement with some studies (Table 1) [7, 8-12]. It has been reported that serum MDA levels were elevated in mild and severe preeclampsia [44] which is in consistence with our results (Table 2). Many 
Table 1. Clinical characteristic, trace elements and malondialdehyde of healthy pregnant women and preeclampsia patients.

\begin{tabular}{|c|c|c|c|}
\hline Parameters & Healthy pregnant $(\mathrm{n}=50)$ & Preeclampsia groups $(\mathrm{n}=50)$ & $P$ value \\
\hline Maternal age(years) & $27.10 \pm 4.60$ & $26.50 \pm 3.90$ & 0.44 \\
\hline Height (m) & $1.60 \pm 0.09$ & $1.62 \pm 0.06$ & 0.23 \\
\hline Weight $(\mathrm{Kg})$ & $67.30 \pm 10.70$ & $65.70 \pm 15.60$ & 0.56 \\
\hline Pre-pregnant body mass index $(\mathrm{kg} / \mathrm{m} 2)$ & $26.40 \pm 5.0$ & $25.10 \pm 6.04$ & 0.23 \\
\hline Gestational age (weeks) & $31.50 \pm 3.60$ & $30.80 \pm 3.30$ & 0.35 \\
\hline Systolic blood pressure $(\mathrm{mmHg})$ & $115.20 \pm 5.70$ & $148.0 \pm 9.60$ & 0.0001 \\
\hline Diastolic blood pressure $(\mathrm{mmHg})$ & $76.0 \pm 6.06$ & $98.60 \pm 10.40$ & 0.0001 \\
\hline Copper (mg/L) & $1.30 \pm 0.34$ & $2.40 \pm 0.64$ & 0.0001 \\
\hline Zinc (mg/L) & $0.73 \pm 0.33$ & $0.71 \pm 0.26$ & 0.76 \\
\hline Copper/ Zinc & $2.28 \pm 1.17$ & $3.85 \pm 1.80$ & 0.0001 \\
\hline Malondialdehyde $(\mathrm{n} \mu \mathrm{mol} / \mathrm{L})$ & $2.95 \pm 1.41$ & $4.62 \pm 1.17$ & 0.0001 \\
\hline
\end{tabular}

Table 2. Clinical characteristic, trace elements and malondialdehyde of healthy pregnant women and patients with mild and severe preeclampsia.

\begin{tabular}{|c|c|c|c|c|}
\hline Parameters & $\begin{array}{l}\text { Healthy pregnant } \\
\text { group }(\mathrm{n}=50)\end{array}$ & $\begin{array}{l}\text { Mild Preeclampsia } \\
\text { group }(n=35)\end{array}$ & $\begin{array}{l}\text { Severe Preeclampsia } \\
\text { group }(n=15)\end{array}$ & $\mathrm{P}$ value \\
\hline Maternal age(years) & $27.18 \pm 4.6$ & $27.0 \pm 4.1$ & $25.40 \pm 3.5$ & 0.36 \\
\hline Height (m) & $1.60 \pm 0.09$ & $1.62 \pm 0.09$ & $1.61 \pm 0.05$ & 0.44 \\
\hline Weight (Kg) & $67.32 \pm 10.70$ & $62.82 \pm 11.90$ & $72.66 \pm 21.10$ & 0.049 \\
\hline Gestational age (weeks) & $31.50 \pm 3.60$ & $31.08 \pm 3.50$ & $30.40 \pm 3.10$ & 0.61 \\
\hline Systolic blood pressure (mmHg) & $115.20 \pm 5.70$ & $142.30 \pm 4.20$ & $161.30 \pm 3.50$ & 0.0001 \\
\hline Diastolic blood pressure $(\mathrm{mmHg})$ & $76.0 \pm 6.10$ & $92.85 \pm 5.70$ & $112.0 \pm 5.60$ & 0.0001 \\
\hline Copper (mg/L) & $1.32 \pm 0.34$ & $2.26 \pm 0.48$ & $2.70 \pm 0.85$ & 0.0001 \\
\hline Malondialdehyde $(\mathrm{n} \mu \mathrm{mol} / \mathrm{ml})$ & $2.96 \pm 1.40$ & $4.50 \pm 1.20$ & $4.92 \pm 0.86$ & 0.0001 \\
\hline
\end{tabular}

studies showed significant elevations in serum MDA levels in both preeclampsia and healthy pregnant women [7, 45-47,]. These findings are not in agreement with our studies and some other studies [7, 48-50]. This study shows that preeclampsia is associated with oxidative stress which is in agreement with the study of other researchers who revealed that oxidative stress increased in preeclampsia [51, 52]. The elevation of serum MDA shows the significance of additional oxidative stress process which occur in preeclampsia patients. Increased level of MDA in preeclampsia women suggest that excessive MDA production may play an important role in the pathophysiology of these patients.

Alteration in level of trace element may play an important role in the development of preeclampsia. Some studies have indicated that there is a significant alteration in serum levels of $\mathrm{Cu}$ and $\mathrm{Zn}$ in healthy pregnancies $[21,53,55]$. $\mathrm{Zn}$ levels inclined to become lower in normal pregnancies [53]. It has been reported that higher concentrations of $\mathrm{Cu}$ and lower concentrations of $\mathrm{Zn}$ were observed in circulation of preeclampsia patients when compared with healthy pregnant subjects $[54,56]$. Studies have shown that zinc concentrations increased in preeclampsia patients when compared with healthy pregnant women [58, 59]. Studies of Diaz et al. [30] and Harma et al. [59] also showed an increased serum zinc concentration and studies of Adeniyi [60], Ajayi [58], and Borella et al. [57] indicated a high plasma zinc concentration. Studies of Mahomed and et al. [61] indicated an increase in leukocyte zinc. Adeniyi [60] reported decreased zinc in placental tissue but an increase in plasma zinc concentration. Many studies 
Table 3. Parameters correlated with serum zinc, copper, malondialdehyde and Copper/ Zinc ratio of preeclampsia patients.

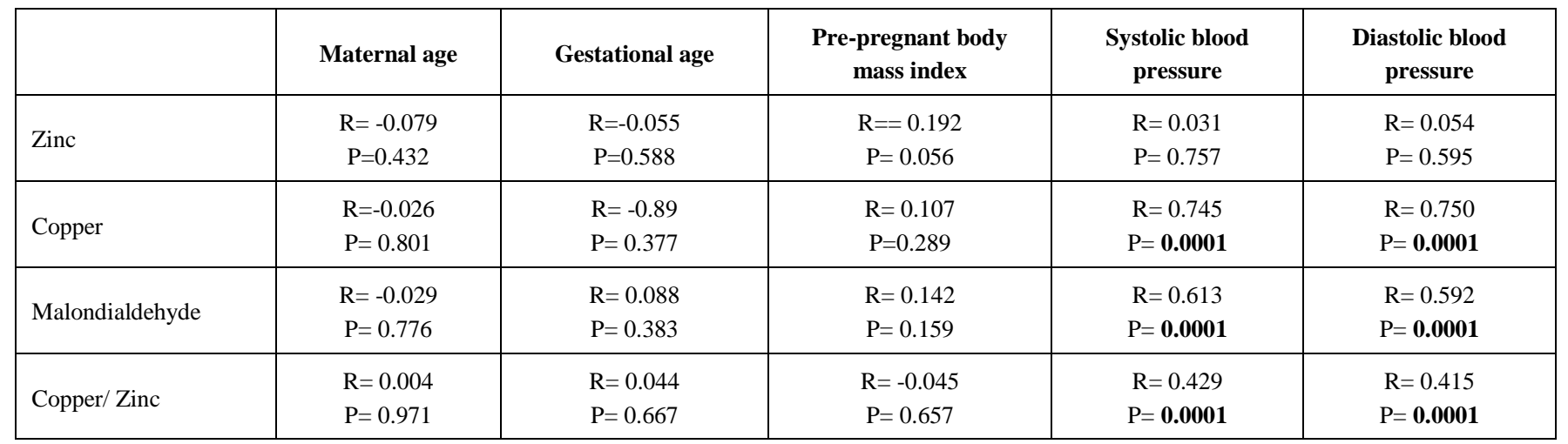

R Spearman correlation coefficient

indicated association of trace elements with the etiology of preeclampsia [33, 62]. Studies have been shown that changes in zinc levels are associated with different obstetric diseases [57] and it has admitted that variation in zinc levels cause a harmful effect on fetal growth [31]. Reduction of zinc concentration may depend on decreased levels of zinc binding protein. A study showed that $\mathrm{Zn}$ deficiencies in pre-eclampsia indicate no association with hemodilution [63]. Some studies have revealed that plasma copper concentration were high $[7,30]$, low $[18,33,61,64]$ and unchanged [65] in preeclampsia women. In the present study, serum level of $\mathrm{Cu}$ was significantly higher in women with preeclampsia when compared to healthy pregnant women which is not in agreement with other studies (Table 1) $[18,33,61,64,65]$. The possible reasons of copper alterations may be associated with the hormonal, metabolic and enzymatic variations in preeclampsia patients [66]. The increase in copper concentrations in pregnancy is associated with copper carrying protein [24]. There was positive significant correlation between copper, copper /zinc ratio and MDA with systolic and diastolic blood pressure (Table 3 ). These parameters may be important factors in early diagnosis of preeclampsia patients and reduction of pathogenesis of this disease in women.

\section{CONCLUSION}

This study showed that increased copper, copper /zinc ratio and MDA and positive significant correlation of these factors with systolic and diastolic blood pressure may be related to the development of hypertensive disorders. Preeclampsia is associated with elevated concentrations of copper and MDA production. Increased levels of copper and MDA in preeclampsia women suggest that these factors may play a significant role in the pathophysiology of this disease. Copper can produce the highly reactive hydroxyl radical. The generation of this radical can begin lipid peroxidation process which may cause endothelial cell damage. Increased levels of copper and MDA could be a marker for the risk of preeclampsia before the beginning of medical findings. Supplementation of different antioxidants may be useful to normalize the formation of free radicals produced by increased levels of copper and MDA. This supplementation may be reducing the risk of preeclampsia in women.

\section{CONFLICT OF INTEREST}

The authors confirm that this article content has no conflict of interest.

\section{ACKNOWLEDGEMENTS}

Declared none.

\section{REFERENCES}

[1] Zeeman G.G.; Dekker G.A.; Van Geijn H.P.; Kraayenbrink A.A. Endothelial function in normal and pre-eclamptic pregnancy: a hypothesis. Eur. J. Obstet. Gynecol. Reprod. Biol., 1992, 43, 11322.

[2] MacGillivray I. Pre-eclampsia: the hypertensive disease of pregnancy. Saunders, 1983.

[3] Ghulmiyyah L.; Sibai B. Maternal mortality from preeclampsia/ eclampsia. Semin. Perinatol., 2012, 36(1), 56-59.

[4] Yaliwal R.G.; Jaju P.B.; Vanishree M. Eclampsia and perinatal outcome: a retrospective study in a teaching hospital. J. Clin. Diagn. Res., 2011, 5(5), 1056-1059.

[5] WHO. Make every mother and child count. World Health Report. Geneva: WHO; 2005.

[6] Lu J.F.; Nightingale C.H. Magnesium sulfate in eclampsia and preeclampsia: pharmacokinetic principles. Clin. Pharmacokinet., 2000, 38(4),305-314.

[7] Ilhan N.; Ilhan N.; Simsek M. The changes of trace elements, malondialdehyde levels and superoxide dismutase activities in pregnancy with or without preeclampsia. Clin. Biochem., 2002, 35, 393-397.

[8] Kharb S. Lipid peroxidation in pregnancy with preeclampsia and diabetes. Gynecol. Obstet. Invest., 2000, 50, 113-116.

[9] Hubel C.A.; Roberts J.M.; Taylor R.N.; Musci T.J.; Rogers G.M.; McLaughlin M.K. Lipid peroxidation in pregnancy: new perspectives on preeclampsia. Am. J. Obstet. Gynecol., 1989, 161, 1025-1034.

[10] Wu J.J. Lipid peroxidation in preeclamptic and eclamptic pregnancies. Eur. J. Obstet. Gynecol. Reprod. Biol., 1996, 64, 5154.

[11] Gratacos E.; Casals E.; Deulofeu R.; Cararach V.; Alonso P.L.; Fortuny A. Lipid peroxide and vitamin $\mathrm{E}$ patterns in pregnant women with different types of hypertension in pregnancy. Am. J. Obstet. Gynecol., 1998, 178, 1072-1076.

[12] Loverro G.; Greco P.; Capuano F.; Carone D.; Cormio G.; Selvaggi L. Lipoperoxidation and antioxidant enzymes activity in pregnancy complicated with hypertension. Eur. J. Obstet. Gynecol. Reprod. Biol., 1996, 70, 123-127.

[13] Walsh S.W.; Wang Y. Secretion of lipid peroxides by the human placenta. Am. J. Obstet. Gynecol., 1993, 169, 1462-1466.

[14] Skoczylas-Pietrzyk M.; Stryjecka-Zimmer M., Oleszczuk J. Lipid and protein peroxidation process and catalase activity in preeclamptic placenta. Ginekol. Pol., 1998, 69, 902-908. 
[15] Wiktor H.; Kankofer M. Assessment of lipid peroxidation intensification in normal and preeclamptic placentas. Ginekol. Pol., 2001, 72, 1217-1221.

[16] Jain S. Membrane lipid peroxidation in erythrocytes of the newborn. Clin. Chem. Acta., 1986, 161, 301e6.

[17] Chambers J.C.; Fusi L.; Malik I.S.; Haskard D.O.; De Swiet M.; Kooner J.S. Association of maternal endothelian dysfunction with pre-eclampsia. JAMA, 2001, 285(12), 1607e12.

[18] Akinloye O.; Oyewale O.J.; Oguntibeju O.O. Evaluation of trace elements in pregnant women with pre-eclampsia. Afr. $J$. Biotechnol., 2010, 9(32), 5196-5202.

[19] Roberts J.M.; Balk J.L.; Bodner L.M.; Belizan J.M.; Berge E.; Martinez A. Nutrient involvement in pre-eclampsia. J. Nutr., 2003, 133(55):1684-1692.

[20] Rathore S.; Gupta A.; Batra H.S.; Rathore R. Comparative study of trace elements and serum ceruloplasmin level in normal and pre-eclamptic pregnancies with their cord blood. Biomed. Res., 2011, 22, 207-10.

[21] Caughey A.B.; Stotland N.E.; Washington A.E.; Escobar G.J. Maternal ethnicity, paternal ethnicity and parental ethnic discordance: predictors of pre-eclampsia. Obstet. Gynecol., 2005, 106, 156-161.

[22] Fang Y.Z.; Yang S.; Wu G. Free radicals, antioxidants, and nutrition. Nutrition, 2002, 18, 872-879.

[23] Fukada T.; Yamasaki S.; Nishida K.; Murakami M.; Hirano I. Zinc homeostasis and signaling in health and diseases: zinc signaling. $J$. Biol. Inorg. Chem., 2011, 16, 1123-1134.

[24] Fukada T.; Kambe T. Molecular and genetic features of zinc transporters in physiology and pathogenesis. Metallomics., 2011, 3, 662-674.

[25] Hojyo S.; Fukada T.; Shimoda S.; OhashiW.; Bin B.; Koseki H.; Hirano T. The zinc transporter SLC39A14/ZIP14 controls Gprotein coupled receptor-mediated signaling required for systemic growth. PLoS One., 2011, 6(3), e18059.

[26] Bader A.A.; Hussain T.; Mosawi M.A.; Otaibi M.; Abul H.; Khalifa D.; Dashti H. Serum zinc and copper concentrations in pregnant women from Kuwait. J. Trace. Elem. Exp. Med., 1997, 10, 209-215.

[27] Jain S.; Sharma P.; Kulshreshtha S.; Mohan G.; Singh S. The role of serum calcium, magnesium, and zinc in pre-eclampsia. Biol. Trace elem. Res., 2010, 133(2), 162-170.

[28] Bahadoran P.; Zendehdel M.; Movahedian A.; Zahraee R.H. The relationship between serum zinc level and pre-eclampsia. Iran J. Nurs. Midwifery Res., 2010, 15, 120-124.

[29] Brophy M.H.; Harris N.F.; Crawford I.L. Elevated copper and lowered zinc in the placentae of pre-eclamptics. Clin. Chim. Acta, 1985, 145, 107-11.

[30] Diaz E.; Halhali A.; Luna C.; Diaz L.; Avila E.; Larrea F. Newborn birth weight correlates with placental zinc, umbilical insulin-like growth factor I, and leptin levels in preeclampsia. Arch. Med. Res., 2002, 33, 40-7.

[31] Adam B.; Malatyalioglu E.; Alvur M.; Talu C. Magnesium, zinc and iron levels in preeclampsia. J. Matern. Fetal. Med., 2001, 10, 246-50.

[32] Kumru S.; Aydin S.; Simsek M.; Sahin K.; Yaman M. Comparison of Serum Copper, Zinc, Calcium, and Magnesium Levels in Pre-Eclamptic and Healthy Pregnant Women. Biol. Trace Elem. Res., 2003, 94, 105-12.

[33] Ugwuja E.I.; Ejikeme B.N.; Ugwuja N.C.; Obeka N.C.; Akubugwo E.I.; Obidoa O. Comparison of Plasma Copper, Iron and Zinc Levels in Hypertensive and Non-hypertensive Pregnant Women in Abakaliki, South Eastern Nigeria. Pak J. Nutr., 2010, 9, 1136-40.

[34] James D.K.; Seely P.J.; Weiner C.P.; Gonlk B. High risk pregnancy: management options. $3^{\text {rd }}$ ed, Philadelphia, Sauders., 2006, 920-925.

[35] Nbofung C.M.; Atinmo T.; Omololu A. Neonatal, maternal and intrapartum factors and their relationship to cord and maternal plasma trace element concentration. Biol. Trace Elem. Res., 1986, 9, 209.

[36] Bolte A.C.; Van Geijn H.P.; Dekker G.A. Management and monitoring of severe preeclampsia. Eur. J. Obstet. Gynecol. Reprod. Biol., 2001, 96, 8-20.

[37] World Health Organization. Prevention and Management of the Global Epidemic of Obesity. Report of the WHO Consultation on Obesity. WHO: Geneva, 1998 (Technical Report Series, No. 894).
[38] Satoh, K. Serum lipid peroxide in cerebrovascular disorders determined by new colorimetric method. Clin. Chim. Acta., 1978, 90: 37-43.

[39] Tuschl K.; Clayton P.T.; Gospe S.M.; Gulab S.; Ibrahim S.; Singhi P.; Aulakh R. Syndrome of hepatic cirrhosis, dystonia, polycythemia, and hypermanganesemia caused by mutations in SLC30A10, a manganese transporter in man. Am. J. Hum Gene., 2012, 90(3), 457-466.

[40] Quadri M.; Federico A.; Zhao T.; Breedveld G.J.; Battisti C.; Delnooz C. Mutations in SLC30A10 cause parkinsonism and dystonia with hypermanganesemia, polycythemia, and chronic liver disease. Am. J. Hum Gene., 2012, 90(3), 467-477.

[41] Dekker G.A.; Sibai B.M. Etiology and pathogenesis of preeclampsia: current concepts. Am. J. Obstet. Gynecol., 1998, 179, 1359-1375.

[42] Taylor R.N. Review: immunobiology of preeclampsia. Am. J. Reprod. Immunol., 1997, 37, 79-86.

[43] Gratacos E. Lipid-mediated endothelial dysfunction: a common factor to preeclampsia and chronic vascular disease. Eur. J. Obstet. Gynecol. Reprod. Biol., 2000, 92, 63-66.

[44] Serdar Z.; Gur E.C.; olakogullar M.; Develioglu O.; Sarandol E. Lipid and protein oxidation and antioxidant function in women with mild and severe preeclampsia. Arch. Gynecol. Obstet., 2003, $268,19-25$.

[45] Serdar Z.; Gur E.; Develioglu O. C.; olakogullari M.; Dirican M. Placental and decidual lipid peroxidation and antioxidant defenses in preeclampsia lipid peroxidation in preeclampsia Pathophysiology, 2002, 9, 21-5.

[46] Kumar C.A.; Das U.N. Lipid peroxides, antioxidants and nitric oxide in patients with preeclampsia and essential hypertension. Med. Sci. Monit., 2000, 6, 901-7.

[47] El-Salahy E.M.; Ahmet M.I.; El-Gharieb A.; Tawfik H. New scope in angiogenesis: role of vascular endothelial growth factor (VEGF), $\mathrm{NO}$, lipid peroxidation, and vitamin $\mathrm{E}$ in the pathophysiology of preeclampsia among Egyptian females. Clin. Biochem., 2001,34, 323-9.

[48] Aydin S.; Benian A.; Madazli R.; Uludag S.; Uzun H. and Kaya S. Plasma malondialdehyde, superoxide dismutase, sE-selectin, fibronectin, endothelin 1 and nitric oxide levels in women with preeclampsia, Eur. J. Obstet. Gynecol. Reprod. Biol., 2004, 113, 21-25.

[49] Atamer Y.; Kocyigit Y.; Yokus B.; Atamer A. and Erden A. C. Lipid peroxidation, antioxidant defense, status of trace metals and leptin levels in preeclampsia, Eur. J. Obstet. Gynecol. Reprod. Biol., 2005, 119, 60-66.

[50] Wang Y. and Wals S. W. Antioxidant activities and mRNA expression of superoxide dismutase, catalase and glutathione peroxidase in normal and preeclamptic placentas, J. Soc. Gynecol. Invest., 1996, 3, 179-184.

[51] Witztum J. The oxidation hypothesis of atherosclerosis. Lancet, 2001, 344, 793-95.

[52] Walker J.J. Pre-eclampsia. Lancet, 2000, 356, 1260-5.

[53] Czupryn M., Falchuk K.H.; Stankiewicz A.; Vallee B.L. A Euglena gracilis zinc endonuclease. Biochemistry., 1993, 32(5), 1204-1211.

[54] Howlader M.Z.H.; Parveen S.; Tamanna S.; Khan T.A.; Begum F. Oxidative stress and antioxidant status in neonates born to preeclamptic mother. J. Trop. Ped., 2009, 55(6), 363-367.

[55] Kishwara S.; Tanira S.; Omar E.; Wazed F.; Ara S. Effects of preeclampsia on perinatal outcome - a study done in the specialized urban hospital set up in Bangladesh. Bangladesh Med., J., 2011, 40(1), 33-36.

[56] Mbah A.K.; Kornosky J.L.; Kristensen S.; August E.M.; Alio A.P.; Marty P.J.; Belogolovkin V.; Bruder K.; Salihu H.M.Super-obesity and risk for early and late preeclampsia. BJOG., 2010,117, 9971004.

[57] Borella P.; Szilagy A.; Than G.; Csaba I.; Giardiano A.; Faccinetti F. Maternal plasma concentrations of magnesium, calcium, zinc and copper in normal and pathological pregnancies. Sci. Total Environ., 1990, 99, 67-76.

[58] Ajayi G. Concentrations of calcium, magnesium, copper, zinc and iron during normal and EPH-gestosis pregnancy. Trace Elem. Med., 1993, 10, 151-2.

[59] Harma M., Harma M. and Kocyigit A.Correlation between maternal plasma homocysteine and zinc levels in preeclamptic women, Biol. Trace Elem. Res., 2005, 104, 97-106. 
[60] Adeniyi F. A. The implications of hypozincemia in pregnancy, Acta Obstet. Gynecol., Scand., 1987, 66, 579-581.

[61] Mahomed K.; Williams M.A.; Woelk G.B.; Mudzamiri S.; Madzime S.; King I.B.; Bankson D.D. Leukocyte selenium, zinc, and copper concentrations in preeclamptic and normotensive pregnant women. Biol Trace Elem. Res., 2000, 75, 107-18.

[62] Bringman J.; Gibbs C.; Ahokas R. Differences in serum calcium and magnesium between gravidas with severe pre-eclampsia and normotensive controls. Am. J. Obstet. Gynecol., 2006, 195, 148.

[63] Farzin L.; Sajadi F. Comparison of serum trace element levels in patients with or without pre-eclampsia J. Res. Med. Sci., 2012, 17, 938-941.
[64] Shahid Sarwar S.; Ahmed A.; Shahid Ullah M.; Humayun Kabir H.; Rahman G. K. M.; Abul Hasnat A.; Safiqul Islam M. Comparative Study of Serum Zinc, Copper, Manganese, and Iron in Preeclamptic Pregnant Women. Biol. Trace Elem. Res., 2013, 154, 14-20.

[65] Prema K. Predictive value of serum copper, and zinc in normal, and abnormal pregnancy. Indian J. Med. Res., 1980, 71, 554-60.

[66] Davey D.A.; MacGillivray I. The classification and definition of hypertension disorders in pregnancy. Am. J. Obstet. Gynecol., 1988, $158,892-8$.

(C) Rafeeinia et al.; Licensee Bentham Open.

This is an open access article licensed under the terms of the Creative Commons Attribution Non-Commercial License (http://creativecommons.org/licenses/ by-nc/3.0/) which permits unrestricted, non-commercial use, distribution and reproduction in any medium, provided the work is properly cited. 